\title{
Riqueza e distribuição espaço-temporal de anuros em um remanescente de Floresta de Araucária no sudeste do Paraná
}

\author{
Carlos E. Conte \& Denise de C. Rossa-Feres
}

Programa de Pós-graduação em Biologia Animal, Departamento de Zoologia e Botânica, Universidade Estadual Paulista. Rua Cristóvão Colombo 2265, 15054-000 São José do Rio Preto, São Paulo, Brasil.

E-mail: kadu_conte@yahoo.com.br; denise@ibilce.unesp.br

\begin{abstract}
Anuran richness and spatial-temporal distribution along an Araucária Forest remnant in southeastern Paraná State, Brazil. Species richness, spatial distribution and the seasonal occurrence of anurans (adults and tadpoles) were studied throughout 15 months in an Araucaria forest remnant at Fazenda Rio Grande, Paraná State, Brazil. Thirty-two species were registered, which corresponds to the third largest anuran richness in Paraná State. The spatial distribution of the species was not uniform between habitats sampled: $46 \%$ of the species were associates with opened areas, occurring exclusively in habitats of open areas and/or in forest edges, 34\% were associated with forest habitats, occurring, in habitats forest and/or forest edge, while that $13 \%$ were classified as generalists as they occurred in open formations, at the edge and interior of the forest fragments. The reproductive period of the species was correlated with rainfall, since $80 \%$ of the species were found in breeding activity the rainy season. About $40 \%$ of the registered anuran species were associated on the habitat features provided by the forest cover which reinforces the importance of conservation of Araucaria Forest remnants.

KEY WORDS. Anura; conservation; seasonality; site call; tadpoles.
\end{abstract}

RESUMO. A riqueza de espécies, a distribuição espacial e a ocorrência sazonal de anuros (adultos e girinos) foram determinadas ao longo de 15 meses, em um remanescente da floresta de araucária no município de Fazenda Rio Grande, Paraná, Brasil. Foram registradas 32 espécies, sendo essa a área com a terceira maior riqueza registrada no Estado. A distribuição espacial das espécies não foi uniforme entre os hábitats amostrados: $46 \%$ das espécies foram associadas à área aberta, ocorrendo exclusivamente em hábitats de área aberta e/ou em borda florestal, 34\% foram associadas à hábitats florestais, ocorrendo em hábitats florestais ou de borda florestal, enquanto que $13 \%$ foram classificadas como generalistas, pois ocorreram em área aberta, borda e interior de floresta. O período reprodutivo dos anuros foi fortemente relacionado com a chuvosa, quando cerca de $80 \%$ das espécies foram registradas em atividade de vocalização. Cerca de $40 \%$ das espécies registradas são associadas à hábitats florestais, o que reforça a urgência da preservação desses remanescentes de Floresta de Araucária. PALAVRAS-CHAVE. Anura; conservação; girinos; sazonalidade; sítio de vocalização.

A Floresta Ombrófila Mista, ou Floresta de Araucária originalmente cobria $177.600 \mathrm{~km}^{2}$ do território nacional, mais de 30\% da Região Sul do Brasil, constituindo uma das principais fitofisionomias dessa região (Leite \& KLeIN 1990). No Paraná ocupava uma área de $75.000 \mathrm{~km}^{2}$ (37\% do território) (MACHADO \& Siqueira 1980, MaACK 1981). Hoje, suas porções remanescentes não somam $1 \%$ da cobertura original em estágio avançado de sucessão florestal (BRitez et al. 2000), sucumbindo cada vez mais a pressões como extração de madeira e a substituição da cobertura nativa por reflorestamento com espécies exóticas, em especial Pinus e Eucalyptus (Britez et al. 2000). Como agravante, remanescentes da Floresta de Araucária inseridos em áreas de proteção integral somam apenas 0,09\% da superfície total recoberta por essa floresta (CASTELla et al. 2004).

A fragmentação e remoção de hábitats promovem alterações na abundância e riqueza específica em comunidades e até mesmo declínios e/ou extinções de populações de anuros (Tocher et al. 1997, AlFord \& Richards 1999). Considerando que o conhecimento da anurofauna associada à Floresta de Araucária ainda é muito restrito (Kwet \& Di-Bernardo 1999, Conte \& MAchado 2005, Conte \& Rossa-Feres 2006), neste estudo determinamos a riqueza de espécies, a distribuição espacial e a ocorrência sazonal de adultos e girinos em um fragmento de Floresta de Araucária, no Estado do Paraná, Brasil. 


\section{MATERIAL E MÉTODOS}

\section{Área de estudo}

O estudo foi desenvolvido na Fazenda Experimental Gralha Azul $\left(25^{\circ} 37^{\prime} \mathrm{S}, 2^{\circ} 41^{\prime} \mathrm{S}, 4^{\circ} 15^{\prime} \mathrm{W}, 49^{\circ} 17^{\prime} \mathrm{W}\right)$, pertencente à Pontifícia Universidade Católica do Paraná, no município de Fazenda Rio Grande, sudeste do Paraná, a cerca de 30 km de Curitiba. A Fazenda Experimental Gralha Azul está localizada em uma área originalmente composta por campos limpos, caracterizados por amplas áreas de gramíneas e áreas florestais chamadas de capões de araucária, que nas depressões úmidas, onde havia condições climáticas favoráveis, expandiram-se paulatinamente unindo-se com outros capões, constituindo assim complexos maiores de mata, entremeadas por campos (MAACK 1981). Atualmente a região é representada por um mosaico de diversos estágios sucessionais distintos, submetidos a variados níveis de impactos de origem antrópica (Koenler et al. 1998), em uma área de 876,7 ha, dividida em 41 ha de várzeas, 475,2 ha de floresta e o restante constituído por áreas de agricultura, pastos e edificações (Puc 2007). A altitude varia entre 870 e 920 metros e o clima é subtropical úmido mesotérmico ou Cfb de Köppen, com verões frescos e ocorrência de geadas severas e freqüentes. A média de temperatura nos meses mais quentes é inferior a $22^{\circ} \mathrm{C}$ e a dos meses mais frios é inferior a $18^{\circ} \mathrm{C}$ (Ferreira 1996). A precipitação anual varia de 1.400 a 1.700 $\mathrm{mm}$, com concentração de chuvas no período de outubro a março, porém, sem estação seca definida (Paraná 1987).

\section{Composição e uso de hábitats}

Foram realizadas 15 visitas mensais, com duração de quatro dias cada, no período de janeiro de 2002 a março de 2003 . A cada visita foram empregados quatro métodos para amostragem dos anuros: 1) levantamento em sítio de reprodução (sensu ScotT JR \& WOODWARD 1994), efetuado em seis corpos d'água (Tab. I). O perímetro de cada corpo d'água foi percorrido lentamente, sendo registradas as espécies com machos em atividade de vocali- zação; 2) transecção por busca aural, efetuado em um trecho de $100 \mathrm{~m}$ no interior da floresta (Tab. I), que era percorrido lentamente, em linha reta, sendo registradas as espécies cujos machos vocalizam distantes de corpos d'água; 3) busca ativa, que consistiu na procura dos anfíbios embaixo de troncos e pedras, no interior de bromélias e demais refúgios encontrados no entorno de cada corpo d'água e no interior de floresta, com um esforço de procura $40 \mathrm{~min} /$ pessoa em cada local; 4) amostragem de girinos, realizada com puçá de tela de arame com malha de 3 $\mathrm{mm}^{2}$ e cabo longo, passado por toda a superfície de cada corpo d'água, desde as margens até a parte central. Os dois primeiros métodos foram realizados durante o turno de vocalização das espécies, do crepúsculo até aproximadamente 24 h, e os métodos de busca ativa e amostragem de girinos foram realizados entre 14 e 17 h. Para evitar que a determinação da riqueza de espécies sofresse efeito do turno de vocalização das espécies, a seqüência de amostragem nos diversos hábitats diferiu a cada visita.

A riqueza de espécies na área amostrada, considerando os quatro métodos de amostragem efetuados nos corpos d'água e no trecho em interior de floresta, foi estimada com base na incidência mensal das espécies, por extrapolação da curva de acumulação de espécies pelo índice "Incidence-based Coverage Estimator" (ICE; CHAo \& LeE 1992).

O uso de hábitats pelas espécies de anuros, determinado pelo encontro de machos em atividade de vocalização e/ou de girinos, foi analisado pela aplicação do coeficiente de afinidade de Jaccard, com posterior análise de agrupamento pelo método de média não ponderada (UPGMA) (Krebs 1999). Os agrupamentos foram definidos pelo valor mínimo de 50\% de similaridade.

Exemplares testemunho foram depositados na Coleção Científica de Amphibia (adultos: DZSJRP 8801-8898 e girinos: lotes DZSJRP 774-839) do Departamento de Zoologia e Botânica, Universidade Estadual Paulista, Campus de São José do Rio Preto, São Paulo.

Tabela I. Caracterização dos hábitats amostrados na Fazenda Gralha Azul, Fazenda Rio Grande, Paraná: (PTA) poça temporária em área aberta, (PTF) poça temporária em interior de floresta, (PTB) poça temporária em borda florestal, (BBF) brejo em borda florestal, (TPB) tanque de piscicultura em borda florestal, (TPA) tanque de piscicultura em área aberta, (FLO) trecho em interior de floresta. Tipos de vegetação: (Vhe) herbácea, (Var) arbustiva, (Vab) arbórea, (Vaq) aquática, (Vta) taboa, (Vpl) monoculturas (feijão e soja), (Vbr) bromélias e (Vpt) pteridófitas.

\begin{tabular}{|c|c|c|c|c|c|c|}
\hline \multirow{2}{*}{ Hábitats } & \multirow{2}{*}{ Tipo de vegetação } & \multirow{2}{*}{ Velocidade da água } & \multicolumn{2}{|c|}{ Vegetação no corpo d'água } & \multirow{2}{*}{$\begin{array}{l}\text { Profundidade } \\
\text { máxima (m) }\end{array}$} & \multirow{2}{*}{$\begin{array}{c}\text { Tamanho } \\
\text { máximo (m) }\end{array}$} \\
\hline & & & Interior & Marginal & & \\
\hline PTA & Vhe, Vaq, Vta, Vpl & parada & abundante & abundante & 0,90 & $20 \times 15$ \\
\hline PTF & Vhe,Var,Vab,Vaq,Vbr,Vpt & parada & esparsa & abundante & 0,50 & $8 \times 3$ \\
\hline PTB & Vhe,Var,Vab,Vaq,Vbr,Vpt & parada & ausente & abundante & 0,70 & $10 \times 4$ \\
\hline $\mathrm{BBF}$ & Vhe,Var,Vab, Vbr,Vpt & constante troca & ausente & abundante & 0,20 & $10 \times 8$ \\
\hline TPB & Vhe,Var,Vab,Vaq,Vbr,Vpt & constante troca & ausente & abundante & 1,20 & $100 \times 50$ \\
\hline TPA & Vhe, Vaq, Vta & constante troca & ausente & abundante & 1,00 & $20 \times 15$ \\
\hline FLO & Vhe,Var,Vab, Vbr, Vpt & - & - & - & - & $100^{*}$ \\
\hline
\end{tabular}

* Transecção da borda para o interior da floresta.

Revista Brasileira de Zoologia 24 (4): 1025-1037, dezembro 2007 


\section{Sazonalidade}

O período reprodutivo de cada espécie foi determinado, segundo Conte \& Rossa-Feres (2006), com base no período em que foram registrados machos vocalizando, casais em amplexo, desovas e/ou girinos até o estágio 27 (Gosner 1960). Para os girinos de Hypsiboas faber (Wied-Neuwied, 1821), que atingem grande tamanho ainda em estágios iniciais de desenvolvimento, foram considerados girinos até o estágio 25 (GosNer 1960) com, no máximo, $2 \mathrm{~cm}$ de comprimento total.

A existência de relação entre o número de espécies em atividade de vocalização e os parâmetros climáticos foi verificada por regressão linear múltipla $\left(\mathrm{r}^{2}\right)$, sendo considerados significativos valores de $\mathrm{p} \leqslant 0,05$ (Zar 1999). Foram consideradas as médias mensais dos valores de temperatura (mínima, média e máxima) e de umidade relativa do ar. Para a precipitação pluviométrica foram considerados os valores do dia anterior à data de amostragem e os valores acumulados nos períodos de cinco e de 30 dias antes da data de amostragem. Os dados abióticos foram obtidos na estação climatológica da Fazenda Experimental Gralha Azul, localizada a cerca de $1 \mathrm{Km}$ da área amostrada.

\section{Sítio de vocalização}

O uso de sítio de vocalização foi analisado em duas poças temporárias, uma localizada em área aberta e a outra em área de floresta, pela determinação das seguintes variáveis: 1) distância da margem, medida do macho em atividade de vocalização até a margem mais próxima, 2) tipo de substrato (vegetação herbácea, arbustiva, arbórea, macrófitas, taboas, bromélias, pteridófitas e monoculturas de milho e/ou feijão, solo seco, solo brejoso, serrapilheira, vegetação seca, parcialmente submerso ou flutuando) e 3) altura de empoleiramento (para as espécies cujos machos vocalizam empoleirados na vegetação). A sobreposição no uso do sítio de vocalização foi determinada pela aplicação do índice de similaridade de Morisita-Horn $\left(\mathrm{C}_{\mathrm{H}}\right)$, com posterior análise de agrupamento pelo método de média não ponderada (UPGMA) (Krebs 1999). Nessa análise, foram consideradas somente as espécies cujo número de observações foi maior ou igual a cinco (Rossa-Feres \& JiM 2001). Os agrupamentos foram definidos pelo valor mínimo de $65 \%$ de similaridade, sendo a representação da matriz de similaridade no dendrograma avaliada pela determinação do Coeficiente de Correlação Cofenética (r de Pearson). Esse coeficiente avalia a perda de informações na construção dos dendrogramas, sendo considerada baixa distorção valores de $r \geqslant 0,8$ (Rohlf \& Sokal 1981, Valentin 1995). Para verificar se as variáveis altura de empoleiramento e distância da margem diferiram entre as espécies com alta similaridade no uso de sítio de vocalização, foram utilizados os testes de MannWhitney (U) para pares de espécies e de Kruskal-Wallis (H) para agrupamentos com mais de duas espécies (Ayres et al. 2003), sendo considerados significativos valores de $\mathrm{p} \leqslant 0,05$ (Zar 1999).

\section{RESULTADOS}

\section{Composição e uso de hábitats}

Foram registradas 32 espécies de anuros, pertencentes a sete famílias: Brachycephalidae (1), Bufonidae (2), Cycloramphidae (3), Leiuperidae (3), Leptodactylidae (4), Hylidae (18) e Microhylidae (1) (Tab. II). Desse total, apenas três espécies (Scinax catharinae, Scinax sp. e Cycloramphus bolitoglossus) não foram encontradas em atividade de vocalização. Apesar de $S$. catharinae não ter sido observada em atividade de vocalização, girinos dessa espécie foram encontrados em dois corpos d'água (Tab. III). A curva de acumulação de espécies tende a uma assíntota por volta da décima amostra, entretanto a diferença entre o número total de espécies registradas e estimadas é de três espécies (ICE = 35 espécies, Fig. 1).

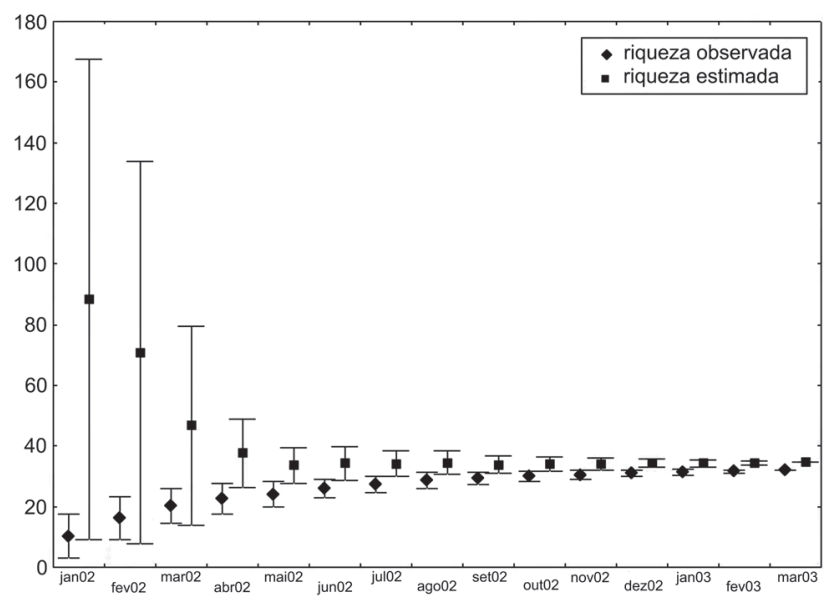

Figura 1. Riqueza observada e estimada (ICE) para 15 períodos de amostragem, realizados entre janeiro de 2002 e março de 2003, na Fazenda Gralha Azul, Fazenda Rio Grande, Paraná.

O número de hábitats utilizados pelas espécies variou de um a seis, enquanto que o número de espécies que ocorreram num mesmo hábitat variou de dois a 19 (Tab. III). O hábitat com maior riqueza de espécies foi a poça temporária em área aberta (19 espécies), enquanto que no trecho em interior da floresta ocorreu a menor riqueza (duas espécies). A análise do uso de hábitat pelas espécies, evidenciou seis agrupamentos (Fig. 2): 1) espécies exclusivas de floresta; 2) espécies exclusivas de borda florestal; 3 ) espécies exclusivas de área aberta; 4) espécies de floresta/borda, que ocorreram tanto nos hábitats florestais quanto nos de borda florestal; 5) espécies generalistas, que ocorreram em hábitats localizados tanto em área aberta quanto no interior de floresta; e 6) espécies de área aberta/borda, que ocorreram tanto em hábitats de área aberta quanto em hábitats de borda florestal. A anurofauna da área estudada foi constituída, em maior proporção (46\%), por espécies associadas à área aberta, sendo $26 \%(n=8)$ exclusivas de área aberta e $20 \%(n=6)$ de área aberta/borda. As espécies associadas à formação florestal representaram $34 \%$ da anurofauna registrada, sendo $7 \%(n=2)$ exclusivas de floresta, $7 \%(n=2)$ exclusivas

Revista Brasileira de Zoologia 24 (4): 1025-1037, dezembro 2007 
Tabela II. Espécies registradas na Fazenda Gralha Azul, Fazenda Rio Grande, Paraná, entre janeiro de 2002 e março de 2003. Métodos de inventário: (1) inventário em sítio de reprodução, 2) transecção por busca aural, (3) busca ativa e (4) amostragem de girinos.

\begin{tabular}{lll}
\hline Família e espécie & Método \\
\hline
\end{tabular}

Brachycephalidae

Eleutherodactylus guentheri (Steindachner, 1867)

2

Bufonidae

Chaunus abei (Baldissera, Caramaschi \& Haddad, 2004) 1,3,4

Chaunus ictericus (Spix, 1824)

Cycloramphidae

Cycloramphus bolitoglossus (Werner, 1897) *

3

Odontophrynus americanus (Duméril \& Bibron, 1841) 1

Proceratophrys aff. avelinoi

Proceratophrys boiei (Wied-Neuwied, 1824)

Hylidae

Leiuperidae

Leptodactylidae

Microhylidae vocalização.
Aplastodiscus perviridis Lutz, 1950

Aplastodiscus albosignatus (Lutz \& Lutz, 1938)

Bokermannohyla circumdata (Cope, 1870)

Dendropsophus microps (Peters, 1872)

Dendropsophus minutus (Peters, 1872)

Dendropsophus sanborni (Schmidt, 1944)

Hypsiboas bischoffi (Boulenger, 1887)

Hypsiboas faber (Wied-Neuwied, 1821)

Hypsiboas prasinus (Burmeister, 1856)

Phyllomedusa distincta Lutz, 1950

Scinax berthae (Barrio, 1962)

Scinax catharinae (Boulenger, 1888) *

Scinax fuscovarius (Lutz, 1925)

Scinax perereca Pombal, Haddad \& Kasahara, 1995

Scinax rizibilis (Bokermann 1964)

Scinax sp. (gr. ruber) *

Sphaenorhynchus surdus (Cochran, 1953)

Trachycephalus imitatrix (Miranda-Ribeiro, 1926)

Physalaemus cuvieri Fitzinger, 1826

Physalaemus gracilis (Boulenger, 1883)

Physalaemus olfersii (Lichtenstein and Martens, 1856)

Leptodactylus aff. marmoratus

Leptodactylus notoaktites Heyer, 1978

Leptodactylus ocellatus (Linnaeus, 1758)

Elachistocleis bicolor (Guérin-Méneville, 1838)

$\left(^{*}\right)$ Espécies cujos machos não foram encontrados em atividade de

1

1,4

1

1,4

$1,3,4$

1

$1,3,4$

$1,3,4$

1,4

1

1

3,4

$1,3,4$

$1,3,4$

1,4

3

1

1,3

$1,3,4$

1

1,4

2

$1,3,4$

1

1,4

,4

Revista Brasileira de Zoologia 24 (4): 1025-1037, dezembro 2007

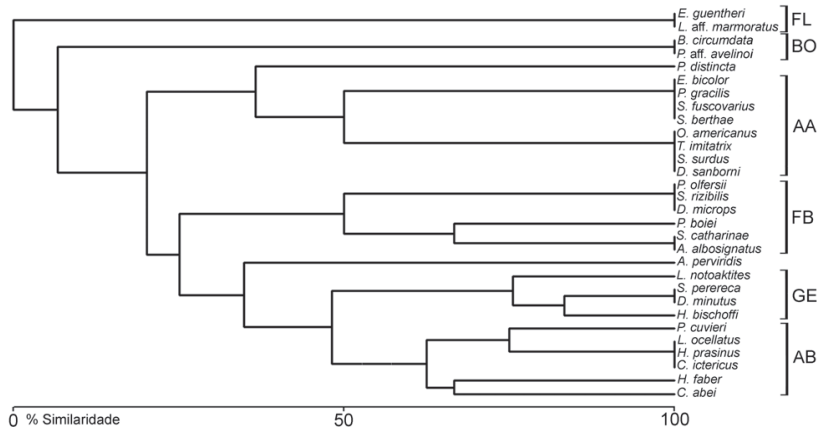

Figura 2. Similaridade (\%) no uso de hábitat entre as 30 espécies registradas em sete hábitats na Fazenda Gralha Azul, Fazenda Rio Grande, Paraná. (AA) Espécies exclusivas de área aberta, ( $A B)$ espécies de área aberta/borda, (BO) espécies exclusivas de borda florestal, (FB) espécies de floresta/borda, (FL) espécies exclusivas de floresta, (GE) generalistas. Coeficiente de correlação cofenético =0,88.

de borda florestal e $20 \%(\mathrm{n}=6)$ de floresta/borda. Apenas $13 \%$ $(\mathrm{n}=4)$ das espécies foram generalistas. Phyllomedusa distincta e Aplastodiscus perviridis (7\%) apresentaram baixa similaridade com as demais espécies em relação ao uso de hábitat e não foram incluídas em nenhum dos agrupamentos formados. A primeira ocorreu em poça temporária tanto de área aberta quanto em interior de floresta e $A$. perviridis em poça e tanque de piscicultura em borda florestal (Tab. III).

\section{Sazonalidade}

Das 32 espécies registradas na região, 29 foram encontradas em atividade de vocalização (Fig. 3). Machos da maioria das espécies vocalizaram em janeiro e fevereiro de 2002 e de agosto de 2002 a fevereiro de 2003, período com maiores valores de precipitação pluviométrica (Fig. 3). Já no período de março a julho de 2002, quando o volume de chuva foi menor (12\% da precipitação anual, que foi de 1858,2 mm), apenas cinco espécies (17\%, $n=29$ espécies) vocalizaram (Fig. 3). Dentre os descritores climáticos considerados, apenas a relação entre a riqueza de espécies em atividade de vocalização e o volume de precipitação acumulado no período de trinta dias anteriores à data de amostragem foi significativa $\left(F=7,7 ; r^{2}=3,64 ; p=0,008\right)$.

Para vinte e três, das 32 espécies registradas, foram encontradas evidências de reprodução (Tab. IV), sendo as espécies classificadas, de acordo com seu padrão reprodutivo, em: I) Anuais: espécies que se reproduziram tanto na estação seca quanto na chuvosa (D. minutus, $H$. bischoffi, $H$. faber, $H$. prasinus e $S$. catharinae); II) De estação fria: espécies que se reproduziram somente no período mais frio e seco do ano (Chaunus abei e C. ictericus); III) De início de estação chuvosa: espécies que se reproduziram somente no início dessa estação, geralmente associadas às primeiras chuvas da estação (S. berthae, T. imitatrix, O. americanus); IV) De estação chuvosa: espécies que se reproduziram ao longo da estação chuvosa (A. albosignatus, D. 
Tabela III. Ocorrência de adultos (A) e de girinos (G) nos sete hábitats amostrados na Fazenda Gralha Azul, Fazenda Rio Grande, Paraná, entre janeiro de 2002 e março de 2003: PTA) Poça temporária em área aberta, (PTF) Poça temporária em interior de floresta, (PTB) Poça temporária em borda florestal, (BBF) Brejo em borda florestal, (TPB) tanque de piscicultura em borda florestal, (TPA) tanque de piscicultura em área aberta, (FLO) trecho em interior de floresta; $(\mathrm{CH})$ categoria de uso do hábitat: $(\mathrm{AA})$ espécies exclusivas de área aberta, $(\mathrm{AB})$ espécies de aberta/borda florestal, (BO) espécies de borda florestal, (FB) espécies de floresta/borda florestal, (FL) espécies florestais estritas e (GE) espécies generalistas; $(-)$ categoria de uso do hábitat não determinado.

\begin{tabular}{|c|c|c|c|c|c|c|c|c|}
\hline Espécie & TPB & PTB & TPA & PTA & PTF & $\mathrm{BBF}$ & FLO & $\mathrm{CH}$ \\
\hline E. guentheri & & & & & & & A & $\mathrm{FL}$ \\
\hline C. abei & G & & & A & & & & $A B$ \\
\hline C. ictericus & A & & $A$ & A & & & & $A B$ \\
\hline O. americanus & & & & A & & & & $\mathrm{AA}$ \\
\hline P. aff. avelinoi & & & & & & $A, G$ & & $\mathrm{BO}$ \\
\hline P. boiei & & $A, G$ & & & $A, G$ & $A, G$ & & $\mathrm{FB}$ \\
\hline A. perviridis & A & A & & & & & & - \\
\hline A. albosignatus & & & & & $A, G$ & $A, G$ & & $\mathrm{FB}$ \\
\hline B. circumdata & & & & & & A & & $\mathrm{BO}$ \\
\hline D. microps & & A & & & $A, G$ & & & $\mathrm{FB}$ \\
\hline D. minutus & AG, & $A, G$ & A & $A, G$ & A & & & GE \\
\hline D. sanborni & & & & A & & & & $\mathrm{AA}$ \\
\hline H. bischoffi & $A, G$ & A & A & $A, G$ & $A, G$ & A & & GE \\
\hline H. faber & $A, G$ & A & & $A, G$ & & & & $A B$ \\
\hline H. prasinus & G & & A & A & & & & $A B$ \\
\hline P. distincta & & & & A & A & & & - \\
\hline S. berthae & & & A & A & & & & AA \\
\hline S. catharinae & & & & & G & G & & FB \\
\hline S. fuscovarius & & & A & $A, G$ & & & & AA \\
\hline S. perereca & $A, G$ & $A, G$ & A & $A, G$ & $A G$, & & & GE \\
\hline S. rizibilis & & $A, G$ & & & A & & & $\mathrm{FB}$ \\
\hline S. surdus & & & & A & & & & AA \\
\hline T. imitatrix & & & & $A$ & & & & AA \\
\hline P. cuvieri & $A, G$ & $A, G$ & A & $A, G$ & & & & $A B$ \\
\hline P. gracilis & & & A & A & & & & AA \\
\hline P. olfersii & & A & & & $A, G$ & & & $\mathrm{FB}$ \\
\hline L. aff. marmoratus & & & & & & & A & $\mathrm{FL}$ \\
\hline L. notoaktites & A & $A, G$ & & $A, G$ & A & & & GE \\
\hline L. ocellatus & A & & A & $A$ & & & & $A B$ \\
\hline E. bicolor & & & A & $\mathrm{A}, \mathrm{G}$ & & & & AA \\
\hline Total & 11 & 11 & 11 & 19 & 11 & 6 & 2 & \\
\hline
\end{tabular}

microps, S. fuscovarius, S. perereca, S. rizibilis, L. notoaktites, $L$. ocellatus, E. guentheri, P. cuvieri, P. olfersii, Proceratophrys aff. avelinoi, $P$. boiei e E. bicolor).

\section{Sítio de vocalização}

Das 12 espécies que vocalizaram na poça temporária em interior de floresta, o sítio de vocalização de Hypsiboas faber, Phyllomedusa distincta, Scinax rizibilis e Physalaemus cuvieri não pode ser analisado, pois apenas um indivíduo de cada espécie foi registrado em atividade de vocalização durante todo o perí- odo estudado. A análise de agrupamento (Fig. 4) separou hilídeos e não hilídeos e apenas um agrupamento, entre os hilídeos, apresentou elevada similaridade: $D$. minutus e $D$. microps, cujos machos vocalizaram preponderantemente empoleirados sobre vegetação marginal herbácea (Tab. V). Entretanto a sobreposição não foi total porque essas espécies diferiram em relação à distância da margem $(\mathrm{U}=27 ; \mathrm{p}=0,05)$ (Tab. VI). Machos de $A$. albosignatus vocalizaram preponderantemente distantes do corpo d'água e com uma maior altura de empoleiramento que as espécies restantes (Tabs VI e VII). Já machos de 


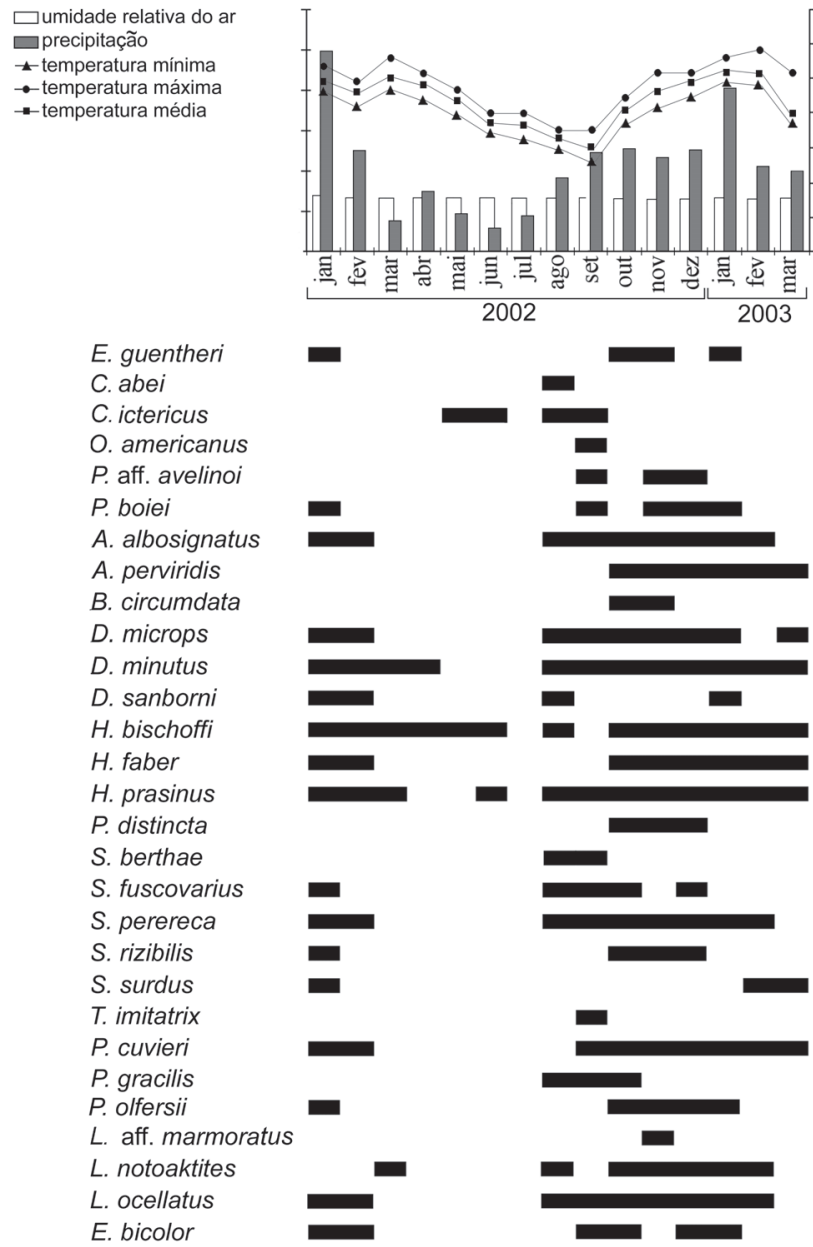

Figura 3. Valores médios de temperatura, umidade relativa do ar e precipitação pluviométrica no período de janeiro de 2002 e março de 2003, e período de atividade de vocalização das espécies de anfíbios anuros registradas na Fazenda Gralha Azul, Fazenda Rio Grande, Paraná e em São José dos Pinhais, Paraná.

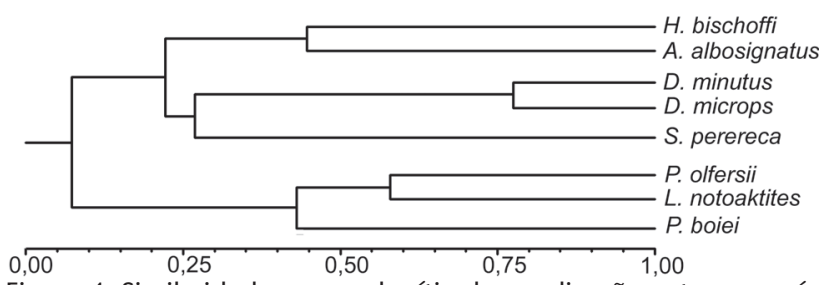

Figura 4. Similaridade no uso de sítio de vocalização entre as espécies que vocalizaram na poça temporária em interior de floresta, na Fazenda Gralha Azul, Fazenda Rio Grande, Paraná. Coeficiente de correlação cofenético $=0,89$.

H. bischoffi e S. perereca vocalizaram empoleirados em alturas semelhantes, entretanto, os de $H$. bischoffi vocalizaram tanto no interior quanto externamente ao corpo d'água, enquanto que os de $S$. perereca foram encontrados vocalizando apenas externamente ao corpo d'água (Tabs VI e VII). As espécies que vocalizaram sobre o solo diferiram principalmente quanto ao tipo de substrato utilizado (Tab. V).

Na poça temporária em área aberta ocorreu a maior riqueza de espécies e o maior número de agrupamentos de espécies com elevada sobreposição no uso do sítio de vocalização (Fig. 5): 1) Machos de H. bischoffi, S. perereca e D. sanborni vocalizaram

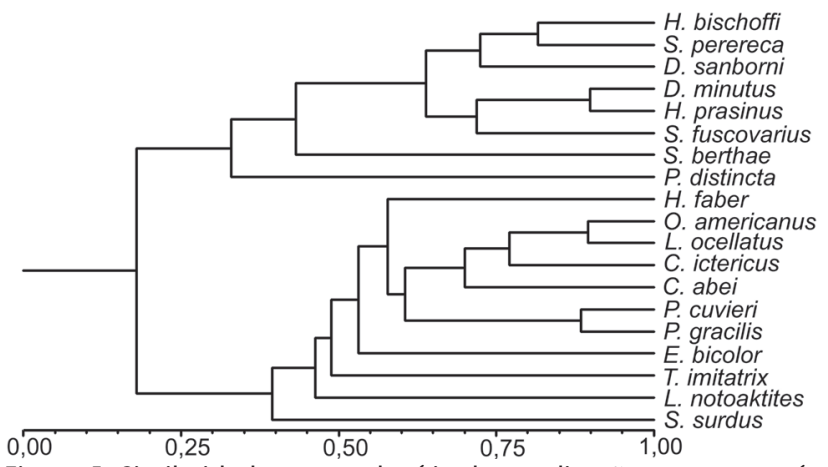

Figura 5. Similaridade no uso de sítio de vocalização entre as espécies que vocalizaram na poça temporária em área aberta, Fazenda Gralha Azul, Fazenda Rio Grande, Paraná. Coeficiente de correlação cofenético $=0,8$.

preponderantemente empoleirados em vegetação herbácea emergente ou sobre taboa (Tab. V), entretanto a sobreposição não foi total porque diferiram em relação à distância da margem $(\mathrm{H}=$ 8,9; $\mathrm{p}=0,01$ ) (Tab. VI); 2) Machos de Dendropsophus minutus, Hypsiboas prasinus e $S$. fuscovarius, vocalizaram preponderantemente empoleirados sobre vegetação herbácea emergente ou sobre taboa, e um grande número de machos das duas primeiras espécies vocalizaram também sobre plantas aquáticas (Tab. V). A sobreposição entre estas espécies também não foi total porque diferiram na altura de empoleiramento $(\mathrm{H}=11,9 ; \mathrm{p}=0,002)$ (Tab. VI); 3) Machos de C. ictericus, C. abei, O. americanus e $L$. ocellatus vocalizaram sobre o solo, à mesma distância da margem, porém diferiram em relação ao tipo de substrato utilizado: a maioria dos machos de $O$. americanus vocalizou sobre vegetação seca, sem contato com a água; machos de C. abei vocalizaram parcialmente submersos com os membros apoiados em galhos ou vegetação submersa, e os de C. ictericus e L. ocellatus vocalizaram parcialmente submersos, com os membros apoiados diretamente no fundo do corpo d'água. Chaunus ictericus vocalizou tanto internamente quanto externamente ao corpo d'água, enquanto machos das demais espécies vocalizaram somente internamente ao corpo d'água (Tabs V e VII); 4) Machos de Physalaemus gracilis e P. cuvieri vocalizaram no interior do corpo d'água, parcialmente submersos em pequenas depressões, diferindo em relação à distância da margem $(U=2,49 ; \mathrm{p}=0,012)$

Revista Brasileira de Zoologia 24 (4): 1025-1037, dezembro 2007 
Tabela IV. Ocorrência sazonal de girinos (G), encontro de casais em amplexo (A), desovas (D) e fêmeas com óvulos (O) das espécies registradas na Fazenda Gralha Azul, Fazenda Rio Grande, Paraná, entre janeiro de 2002 e março de 2003.

\begin{tabular}{|c|c|c|c|c|c|c|c|c|c|c|c|c|c|c|c|}
\hline \multirow{2}{*}{ Espécie } & \multicolumn{12}{|c|}{2002} & \multicolumn{3}{|c|}{2003} \\
\hline & Jan & Fev & Mar & Abr & Mai & Jun & Jul & Ago & Set & Out & Nov & Dez & Jan & $\mathrm{Fev}$ & Mar \\
\hline E. guentheri & & & & & & & & & & $\mathrm{O}$ & $\mathrm{O}$ & & & & \\
\hline C. abei & & & & & & & & A & $D, G$ & & & & & & \\
\hline C. ictericus & & & & & G & $G, D$ & & $G, D$ & $G, D$ & & & & & & \\
\hline O. americanus & & & & & & & & & $\mathrm{O}$ & & & & & & \\
\hline P. aff. avelinoi & & & & & & & & & & & & & $\mathrm{O}, \mathrm{G}$ & & \\
\hline P. boiei & $A, G$ & G & & & & & & & & & G & $A, G$ & G & G & \\
\hline A. albosignatus & & & & & & & & G & G & & & $O, G$ & G & G & \\
\hline D. microps & A & & & & & & & & & $\mathrm{A}, \mathrm{O}$ & & & & G & \\
\hline D. minutus & $A, G$ & $A, G$ & $\mathrm{O}, \mathrm{G}$ & G & G & & & $\mathrm{O}, \mathrm{D}$ & $\mathrm{O}, \mathrm{A}$ & $A, G$ & $\mathrm{~A}, \mathrm{O}$ & $A, G$ & G & $A, G$ & $A, G$ \\
\hline H. bischoffi & A & A & $\mathrm{A}$ & G & G & G & G & G & $A, G$ & $A, G$ & G & $\mathrm{O}$ & $A, G$ & & G \\
\hline H. faber & A & G & G & & & & G & & & $A, G$ & & & $A, G$ & G & G \\
\hline H. prasinus & A & A & D & & & G & & D & A & A & & $\mathrm{O}$ & & & A \\
\hline S. berthae & & & & & & & & & $\mathrm{O}$ & & & & & & \\
\hline S. catharinae & & & & & & G & G & G & G & & G & & & & \\
\hline S. fuscovarius & & $A, G$ & & & & & & & & & & $A, G$ & & & \\
\hline S. perereca & $A, G$ & G & G & & & & & & A & A & A & $\mathrm{O}, \mathrm{G}$ & $\mathrm{O}, \mathrm{G}$ & G & G \\
\hline S. rizibilis & & G & & & & & & & & $\mathrm{O}$ & $\mathrm{O}$ & $\mathrm{O}$ & & & \\
\hline T. imitatrix & & & & & & & & & $\mathrm{O}$ & & & & & & \\
\hline P. cuvieri & $A, G$ & G & G & & & & & & & $A, G$ & A & $A, G$ & $A, G$ & $A, G$ & \\
\hline P. olfersii & & & & & & & & & & & A & $\mathrm{O}$ & G & & \\
\hline L. notoaktites & & & & & & & & & G & & & & G & & \\
\hline L. ocellatus & & & & & & & & & & D & & D & D & & \\
\hline E. bicolor & A & $A, G$ & & & & & & & A & A & & A & & G & G \\
\hline
\end{tabular}

(Tabs V e VI). As demais espécies que vocalizaram nesse hábitat diferiram das anteriores pela altura de empoleiramento e distância da margem (Scinax berthae), pela distância da margem $(P$. distincta), por vocalizarem flutuando ( $T$. imitatrix) ou por vocalizarem tanto empoleiradas quanto sobre o solo $(H$. faber e Sphaenorhynchus surdus). Já entre as espécies que vocalizaram exclusivamente sobre o solo, Leptodactylus notoaktites foi a única cujos machos vocalizaram somente externamente ao corpo d'água, sob vegetação rasteira, enquanto que machos de Elachistocleis bicolor vocalizaram parcialmente submersos a uma distância de aproximadamente $80 \mathrm{~cm}$ da margem (Tabs V, VI e VII), apoiados com os membros anteriores estendidos e o focinho voltado em posição vertical.

\section{DISCUSSÃO}

\section{Composição e uso de hábitats}

As 32 espécies registradas correspondem a $26 \%$ da anurofauna conhecida no Paraná (SEgalla \& Langone 2004), tornando a Fazenda Gralha Azul a localidade com a terceira maior riqueza do Estado, precedida apenas de Telêmaco Borba, com 39 espécies e São José dos Pinhais, com 34 espécies (ConTE \& Rossa-Feres 2006). O número de espécies registradas corresponde a $92 \%$ da riqueza teórica estimada revelando que, possivelmente, com o aumento do esforço de amostragem mais espécies podem ser registradas.

A região onde se insere a área estudada apresenta grande heterogeneidade ambiental, pois o mosaico de hábitats de área aberta e de floresta confere uma elevada variedade de recursos (e.g. sítios de vocalização e oviposição) e de condições físicas (umidade e temperatura). A análise do uso de hábitat evidenciou agrupamentos constituídos por espécies que ocorreram em corpos d'água com características diferentes (permanente ou temporário), mas inseridos na mesma fisionomia vegetal. Assim, a grande riqueza de espécies na área amostrada parece decorrer principalmente da presença de áreas com diferentes formações vegetais que de diferenças nos tipos e na heterogeneidade dos corpos d'água. Esta, por sua vez, foi um reflexo da oferta de tipos de corpos d'água em cada formação vegetal, por exemplo, poças temporárias rasas encontradas apenas no interior da floresta e açudes permanentes de grande profundidade encontrados apenas na área aberta. 
Tabela V. Abundância de machos nos diferentes tipos de substratos utilizados durante a atividade de vocalização em dois corpos d'água temporários na Fazenda Gralha Azul, Fazenda Rio Grande, Paraná, entre janeiro de 2002 e março de 2003. (PTF) Poça temporária em interior de floresta, (PTA) poça temporária em área aberta, (Vhe) vegetação herbácea, (Var) vegetação arbustiva, (Vab) vegetação arbórea e/ou troncos caídos, (Vbr) sobre bromélias, (Vaq) vegetação aquática, (Vpt) pteridófitas, (Vta) taboa (verde ou seca), (Vpl) monoculturas (feijão ou soja), (Sbj) solo brejoso, (Ssr) sobre o solo, serrapilheira ou vegetação seca, (Stc) sobre o solo entre touceiras de gramínea, (Aps) no interior do corpo d'água, parcialmente submerso e apoiado no fundo do corpo d'água, (Aap) no interior do corpo d'água parcialmente submerso e apoiado em vegetação, (Afl) dentro do corpo d'água flutuando, (N) números de sítios determinados por espécie.

\begin{tabular}{|c|c|c|c|c|c|c|c|c|c|c|c|c|c|c|c|}
\hline \multirow{2}{*}{ Espécies } & \multicolumn{8}{|c|}{ Substrato de empoleiramento } & \multicolumn{6}{|c|}{ Sobre o solo ou água } & \multirow[t]{2}{*}{$\mathrm{N}$} \\
\hline & Vhe & Var & Vab & Vbr & Vaq & Vpt & Vta & Vpl & Sbj & Ssr & Stc & Aps & Aap & Afl & \\
\hline \multicolumn{16}{|l|}{ PTF } \\
\hline P. boiei & 0 & 0 & 0 & 0 & 0 & 0 & - & - & 8 & 0 & 0 & - & - & - & 8 \\
\hline A. albosignatus & 5 & 16 & 2 & 0 & 0 & 4 & - & - & 0 & 0 & 0 & - & - & - & 27 \\
\hline D. microps & 21 & 0 & 0 & 3 & 0 & 1 & - & - & 0 & 0 & 0 & - & - & - & 25 \\
\hline D. minutus & 7 & 0 & 0 & 0 & 1 & 0 & - & - & 1 & 0 & 0 & - & - & - & 8 \\
\hline H. bischoffi & 16 & 43 & 8 & 0 & 1 & 14 & - & - & 2 & 0 & 0 & - & - & - & 84 \\
\hline S. perereca & 19 & 0 & 7 & 1 & 0 & 4 & - & - & 0 & 0 & 0 & - & - & - & 31 \\
\hline P. olfersii & 0 & 0 & 0 & 0 & 0 & 0 & - & - & 0 & 7 & 0 & - & - & - & 7 \\
\hline L. notoaktites & 0 & 0 & 0 & 0 & 0 & 0 & - & - & 0 & 0 & 5 & 0 & 0 & 0 & 5 \\
\hline \multicolumn{16}{|l|}{ PTA } \\
\hline C. abei & 0 & - & - & - & 0 & - & 1 & 0 & - & 0 & 0 & 2 & 5 & 0 & 8 \\
\hline C. ictericus & 0 & - & - & - & 0 & - & 0 & 0 & - & 2 & 0 & 7 & 4 & 0 & 13 \\
\hline O. americanus & 0 & - & - & - & 0 & - & 0 & 0 & - & 5 & 0 & 4 & 2 & 1 & 12 \\
\hline D. minutus & 25 & - & - & - & 15 & - & 35 & 1 & - & 0 & 0 & 0 & 3 & 0 & 79 \\
\hline D. sanborni & 3 & - & - & - & 0 & - & 6 & 0 & - & 0 & 0 & 0 & 0 & 0 & 9 \\
\hline H. bischoffi & 24 & - & - & - & 0 & - & 5 & 1 & - & 0 & 0 & 0 & 0 & 0 & 30 \\
\hline H. faber & 4 & - & - & - & 0 & - & 9 & 0 & - & 0 & 0 & 6 & 2 & 0 & 23 \\
\hline H. prasinus & 8 & - & - & - & 7 & - & 29 & 2 & - & 0 & 0 & 0 & 0 & 0 & 46 \\
\hline P. distincta & 0 & - & - & - & 0 & - & 5 & 0 & - & 0 & 0 & 0 & 0 & 0 & 5 \\
\hline S. berthae & 5 & - & - & - & 0 & - & 16 & 0 & - & 0 & 0 & 0 & 1 & 0 & 22 \\
\hline S. fuscovarius & 1 & - & - & - & 0 & - & 5 & 0 & - & 0 & 0 & 0 & 2 & 0 & 8 \\
\hline S. perereca & 24 & - & - & - & 0 & - & 37 & 0 & - & 0 & 0 & 0 & 0 & 0 & 61 \\
\hline S. surdus & 0 & - & - & - & 4 & - & 3 & 0 & - & 0 & 0 & 0 & 0 & 0 & 7 \\
\hline T. imitatrix & 0 & - & - & - & 0 & - & 0 & 0 & - & 0 & 0 & 0 & 0 & 8 & 8 \\
\hline P. cuvieri & 0 & - & - & - & 0 & - & 0 & 0 & - & 2 & 0 & 14 & 0 & 0 & 16 \\
\hline P. gracilis & 0 & - & - & - & 0 & - & 0 & 0 & - & 0 & 0 & 9 & 0 & 0 & 9 \\
\hline L. notoaktites & 0 & - & - & - & 0 & - & 0 & 0 & - & 0 & 15 & 0 & 0 & 0 & 15 \\
\hline L. ocellatus & 0 & - & - & - & 0 & - & 0 & 0 & - & 1 & 0 & 7 & 1 & 0 & 9 \\
\hline E. bicolor & 0 & - & - & - & 0 & - & 0 & 0 & - & 0 & 0 & 20 & 0 & 0 & 20 \\
\hline
\end{tabular}

\section{Sazonalidade}

A maioria das espécies de anuros se reproduz durante períodos restritos do ano, sendo que em regiões sazonais o período reprodutivo é influenciado pelo volume de chuva e pela temperatura (Duellman \& Trueb 1986, Rossa-Feres \& Jim 1994, Arzabe 1999, Prado et al. 2004, Vasconcelos \& Rossa-Feres 2005). A atividade de reprodução dos anuros na área estudada esteve fortemente relacionada com o clima, pois cerca $70 \%$ das espécies foram encontradas em atividade de vocalização e/ou em reprodução no início ou durante a estação chuvosa. Esse é um padrão comum, verificado em outras áreas de Floresta Atlântica (Bertoluci 1998, Bertoluci \& Rodrigues 2002). Apesar disso, a proporção de espécies anuais dentro do bioma atlântico varia de 0\% em regiões com estação seca bem definida como em Rio Claro (Toledo et al. 2003), padrão semelhante ao encontrado em regiões áridas, como por exemplo a caatinga (ARZABE 1999), até $25 \%$ em regiões com elevado volume de chuva e sem estação seca definida como em São José dos Pinhais (CONTE \& Rossa-FerES 2006), semelhante ao encontrado em regiões não sazonais como, por exemplo, Santa Cecília (Crump 1974) (Tab. VIII). O padrão 
Tabela VI. Média \pm desvio padrão (amplitude, N) da altura de empoleiramento e distância da margem das espécies registradas na Fazenda Gralha Azul, Fazenda Rio Grande, Paraná. (PTF) Poça temporária em interior de floresta e (PTA) poça temporária em área aberta.

\begin{tabular}{|c|c|c|c|}
\hline \multirow{2}{*}{ Espécies } & \multirow{2}{*}{$\frac{\text { Empoleiramento }}{\text { Altura }(\mathrm{cm})}$} & \multicolumn{2}{|c|}{ Distância da margem } \\
\hline & & Interna (cm) & Externa $(\mathrm{cm})$ \\
\hline \multicolumn{4}{|l|}{ PTF } \\
\hline P. boiei & $0(n=8)$ & 0 & $12 \pm 8(0-20,8)$ \\
\hline A. albosignatus & $131 \pm 99(10-300,27)$ & $5^{*}$ & $334 \pm 162(20-700,26)$ \\
\hline D. microps & $45 \pm 26(15-150,25)$ & $42 \pm 54(10-150,6)$ & $30 \pm 57(0-200,19)$ \\
\hline D. minutus & $47 \pm 26(0-100,8)$ & $62,5 \pm 61(10-150,3)$ & $17 \pm 17(0-30,5)$ \\
\hline H. bischoffi & $41 \pm 29(0-150,84)$ & $62 \pm 61(10-150,4)$ & $112 \pm 124(0-600,80)$ \\
\hline S. perereca & $49 \pm 27(15-150,31)$ & - & $88 \pm 80(0-250,31)$ \\
\hline P. olfersii & $0 \pm 0(n=7)$ & - & $22 \pm 8(10-30,7)$ \\
\hline L. notoaktites & $0 \pm 0(n=5)$ & $10^{*}$ & $25 \pm 13(10-40,4)$ \\
\hline \multicolumn{4}{|l|}{ PTA } \\
\hline C. abei & $5^{*}$ & $274 \pm 134(100-500,7)$ & - \\
\hline C. ictericus & - & $323 \pm 151(50-600,11)$ & $62 \pm 18(50-75,2)$ \\
\hline O. americanus & $0 \pm 0(n=12)$ & $219 \pm 132(5-400,11)$ & $0^{*}$ \\
\hline D. minutus & $27 \pm 31(0-140,79)$ & $239 \pm 113(50-600,72)$ & $175 \pm 171(20-500,7)$ \\
\hline D. sanborni & $58 \pm 35(30-120,9)$ & $140 \pm 42(80-200,8)$ & $0 *$ \\
\hline H. bischoffi & $53 \pm 29(10-130,30)$ & $178 \pm 85(50-400,23)$ & $83 \pm 65(0-200,7)$ \\
\hline H. faber & $18 \pm 35(0-100,23)$ & $175 \pm 85(10-300,22)$ & $0^{*}$ \\
\hline H. prasinus & $52 \pm 49(0-140,46)$ & $252 \pm 125(5-500,39)$ & $200 \pm 334(0-1000,7)$ \\
\hline S. berthae & $17 \pm 14(0-40,22)$ & $183 \pm 79(30-300,21)$ & $0^{*}$ \\
\hline S. fuscovarius & $44 \pm 55(0-100,8)$ & $136 \pm 90(5-300,7)$ & $500^{*}$ \\
\hline S. perereca & $60 \pm 43(5-130,61)$ & $166 \pm 90(50-400,27)$ & $110 \pm 71(20-250,34)$ \\
\hline S. surdus & $33 \pm 42(0-90,7)$ & $178 \pm 72(70-250,7)$ & - \\
\hline P. distincta & $114 \pm 40(50-140,5)$ & $50 \pm 0(50,2)$ & $0(n=3)$ \\
\hline T. imitatrix & $0 \pm 0(n=8)$ & $214 \pm 38(170-250,8)$ & - \\
\hline P. cuvieri & $0 \pm 0(n=16)$ & $56 \pm 46(10-70,7)$ & $6 \pm 7(0-20,9)$ \\
\hline P. gracilis & $0 \pm 0(n=9)$ & $102 \pm 106(5-250,9)$ & - \\
\hline L. notoaktites & $0 \pm 0(n=15)$ & - & $13 \pm 13(0-40,15)$ \\
\hline L. ocellatus & $0 \pm 0(n=9)$ & $132 \pm 204(0-500,9)$ & - \\
\hline E. bicolor & $0 \pm 0(n=20)$ & $82,5 \pm 57(10-200,18)$ & $5 \pm 7(0-10,2)$ \\
\hline
\end{tabular}

* Valores obtidos para um indivíduo.

de ocorrência sazonal registrado neste estudo, bem como em outras localidades do bioma atlântico (ROSSA-FERES \& JiM 1994, CONTE \& Rossa-Feres 2006), corresponde a um padrão intermediário entre regiões sazonais e regiões tropicais úmidas.

O número de espécies em atividade de vocalização não foi influenciado pela temperatura. Isso provavelmente decorre do fato de em agosto e novembro de 2002 ter ocorrido queda na temperatura, ambas inesperadas para a época, e o número de espécies em atividade de vocalização não acompanhou essas mudanças climáticas. Por outro lado, o número de espécies em atividade de vocalização foi influenciado pelo volume de precipitação. Em março de 2002, quando a precipitação foi de 44,4 mm, estavam em atividade de vocalização machos de ape- nas quatro espécies, ao passo que em março de 2003, quando a precipitação foi de 116,2 $\mathrm{mm}$, machos de nove espécies estavam vocalizando. As chuvas foram responsáveis pela formação de poças temporárias, onde cerca de $80 \%$ das espécies registradas foram encontradas em atividade de vocalização, e onde foram registradas as maiores riquezas de espécies.

\section{Sítio de vocalização}

A segregação que ocorre entre as espécies de anuros durante a atividade reprodutiva está relacionada com as características físicas do hábitat (RABв 1973, CARdoso et al. 1989), com a morfologia e com o tamanho de cada espécie (Crump 1971, Hödl 1977, Rossa-feres \& Jim 2001, Bertoluci \& Rodrigues 2002). 
Tabela VII. Porcentagem (N) da altura de empoleiramento e distância da margem das espécies registradas na Fazenda Gralha Azul, Fazenda Rio Grande, Paraná. (PTF) Poça temporária em interior de floresta, (PTA) poça temporária em área aberta.

\begin{tabular}{|c|c|c|c|c|c|}
\hline & \multicolumn{2}{|c|}{ Empoleiramento (\%) } & \multicolumn{3}{|c|}{ Distância da margem (\%) } \\
\hline & Empoleirados & Solo & Interna & Externa & Na margem \\
\hline \multicolumn{6}{|l|}{ PTF } \\
\hline P. boiei & 0 & $100(8)$ & - & $38(3)$ & $62(5)$ \\
\hline A. albosignatus & $100(27)$ & - & $3(1)$ & $97(26)$ & - \\
\hline D. microps & $100(30)$ & - & $20(6)$ & $44(13)$ & $36(11)$ \\
\hline D. minutus & $89(7)$ & $11(1)$ & $50(4)$ & $25(2)$ & $25(2)$ \\
\hline H. bischoffi & $98(82)$ & $2(2)$ & $5(4)$ & $81(68)$ & $14(12)$ \\
\hline S. perereca & $100(31)$ & - & - & $22(7)$ & $78(24)$ \\
\hline P. olfersii & 0 & $100(7)$ & - & $100(7)$ & - \\
\hline L. notoaktites & 0 & $100(5)$ & $20(1)$ & $80(4)$ & - \\
\hline \multicolumn{6}{|l|}{ PTA } \\
\hline C. $a b e i$ & $12(1)$ & $88(7)$ & $100(8)$ & - & - \\
\hline C. ictericus & - & $100(13)$ & $84(11)$ & $16(2)$ & - \\
\hline O. americanus & - & $100(12)$ & $91(11)$ & - & $9(1)$ \\
\hline D. minutus & $81(64)$ & $19(15)$ & $91(72)$ & $9(7)$ & - \\
\hline D. sanborni & $100(8)$ & - & $87(7)$ & - & $13(1)$ \\
\hline H. bischoffi & $100(30)$ & - & $73(22)$ & $23(7)$ & $4(1)$ \\
\hline H. faber & $39(9)$ & $61(14)$ & $83(19)$ & - & $17(4)$ \\
\hline H. prasinus & $87(40)$ & $13(6)$ & $83(38)$ & $11(5)$ & $6(3)$ \\
\hline S. berthae & $95(21)$ & $5(1)$ & $95(21)$ & - & $5(1)$ \\
\hline S. fuscovarius & $75(6)$ & $25(2)$ & $87(7)$ & $13(1)$ & - \\
\hline S. perereca & $100(61)$ & - & $44(27)$ & $42(26)$ & $14(8)$ \\
\hline S. surdus & $43(3)$ & $57(4)$ & - & $100(7)$ & - \\
\hline P. distincta & $100(5)$ & - & $40(2)$ & - & $60(3)$ \\
\hline T. imitatrix & - & $100(8)$ & $100(8)$ & - & - \\
\hline P. cuvieri & - & $100(16)$ & $44(7)$ & $31(5)$ & $25(4)$ \\
\hline P. gracilis & - & $100(9)$ & $78(7)$ & - & $22(2)$ \\
\hline L. notoaktites & - & $100(15)$ & $66(10)$ & - & $34(5)$ \\
\hline L. ocellatus & - & $100(9)$ & $78(7)$ & - & $22(2)$ \\
\hline E. bicolor & $100(20)$ & - & 95 (19) & - & $5(1)$ \\
\hline
\end{tabular}

As espécies que vocalizaram na poça temporária em interior de floresta apresentaram baixa sobreposição no uso do sítio de vocalização. CARDOSo et al. (1989) encontraram uma maior proporção de espécies da família Hylidae em hábitat florestal e a presença de discos adesivos foi um fator que possibilitou a ocupação vertical do hábitat aumentando, deste modo, a segregação espacial. Entretanto, para as espécies de Hylidae registradas na poça temporária em interior de floresta, verificou-se uma baixa segregação vertical sendo que, das cinco espécies analisadas, apenas machos de A. albosignatus vocalizaram empoleirados a mais de $150 \mathrm{~cm}$ de altura. Ao contrário do esperado, a segregação no sítio de vocalização entre os hilídeos ocorreu ao longo da dimensão horizontal, como registrado para as espécies que vocalizaram sobre o solo.
Já para as espécies que vocalizaram na poça temporária de área aberta, houve grande sobreposição no uso de sítio de vocalização, pois $63 \%$ das 19 espécies apresentaram valores de sobreposição superiores a $65 \%$. A grande similaridade no uso dos sítios de vocalização pode ser atribuída à baixa heterogeneidade estrutural, combinada com o grande número de espécies registradas nesse corpo d'água. Esses fatores podem ter limitado as possibilidades de partilha de sítio de vocalização. Uma elevada sobreposição no uso de sítio de vocalização entre espécies de área aberta também foi registrada em outras localidades de formação vegetal de pequeno porte como no Morro do Ferro, Minas Gerais (CARDoso et al. 1989), e em Nova Itapirema, São Paulo (Rossa-Feres \& Jim 2001). Apesar da elevada sobreposição no uso de sítio de vocalização encontrada na poça temporária 
Tabela VIII. Proporção de espécies anuais, de reprodução restrita à estação chuvosa e que se reproduziram em outros períodos do ano, em 11 localidades com diferentes regimes pluviométricos. Temperatura $\left({ }^{\circ} \mathrm{C}\right.$ ) apresentada como média (amplitude) e precipitação acumulada $(\mathrm{mm})$, durante o período estudado em cada localidade.

\begin{tabular}{|c|c|c|c|c|c|c|}
\hline \multirow{2}{*}{ Localidade } & \multicolumn{3}{|c|}{ Proporção de espécies (\%) } & \multirow{2}{*}{ Precipitação } & \multirow{2}{*}{ Temperatura } & \multirow{2}{*}{ Referência } \\
\hline & Anuais & Estação chuvosa & Outros períodos & & & \\
\hline São José do Bonfim,PB & 0 & 100 & - & 340 & $24,5(21-28)$ & ARZABE (1999) \\
\hline Mauritéia, PB & 0 & 100 & - & 270 & $18,7(15,5-22)$ & ARZABE (1999) \\
\hline Rio Claro, SP & 0 & 80 & 20 & $1833,5^{1}$ & $23,28(18,8-27,8)^{1}$ & Toledo et al. (2003) \\
\hline Nova Itapirema, SP & 7,4 & 92,6 & - & 417 & $24,6(21-27)$ & Vasconcelos \& Rossa-Feres (2004) \\
\hline Boracéia, SP & 15 & 70 & 15 & 1747,3 & $?$ & BeRtoluCI \& RodRIGUes (2002) \\
\hline Londrina, PR & 17 & 61 & 17 & $1880,8^{2}$ & $21,8(11,3-28,9)^{2}$ & BernaRDE \& ANJos (1999) \\
\hline Botucatu, SP & 32 & 67 & - & $?$ & $?$ & Rossa-Feres \& Jim (1994) \\
\hline Intervales, SP & 16 & 76 & 8 & 1755,6 & $19,6(16-23)$ & BERTOLUCI (1998) \\
\hline Fazenda Rio Grande, PR & 22 & 71 & 7 & 1858,2 & $18,8(12-25)$ & Presente estudo \\
\hline São José dos Pinhais, PR & 25 & 68 & 7 & 2263 & $17(9-27)$ & Conte \& Rossa-Feres (2006) \\
\hline Santa Cecília, Equador & 33 & 39 & 28 & 4279 & $26,5(18-35)$ & CRUMP (1974) \\
\hline
\end{tabular}

Os dados climáticos foram extraídos dos artigos ou obtidos em: ${ }^{1}$ CEAPL - Centro de Análise e Planejamento Ambiental, Rio Claro e ${ }^{2}$ IAPAR - Instituto Agronômico do Paraná, Londrina.

de área aberta, que decorreu principalmente da sobreposição na altura de empoleiramento, o sítio de vocalização das espécies diferiu no tipo de substrato e na distância da margem, resultando em sobreposição parcial no uso do sítio de vocalização. Diferenças nos tipos de substratos e na distância da margem também foram detectadas por RossA-FEREs \& JIM (2001), entre espécies que apresentaram grande sobreposição na altura de empoleiramento. Este fenômeno, no qual espécies que ocupam uma mesma posição ao longo de uma dimensão do nicho ecológico tendem a diferir ao longo de outra dimensão, é denominado complementaridade de nicho (BEGON et al. 2006). Na área estudada encontramos evidências de complementaridade de nicho tanto para as espécies que vocalizaram empoleiradas quanto para aquelas que vocalizaram sobre o solo: $H$. bischoffi, $S$. perereca e $D$. sanborni vocalizaram sobre o mesmo tipo de substrato e na mesma altura de empoleiramento, mas diferiram na distância da margem; o sítio de vocalização de $D$. minutus, $H$. prasinus e $S$. fuscovarius foi estabelecido à mesma distância da margem e no mesmo tipo de substrato, mas diferiu na altura de empoleiramento; Physalaemus cuvieri e $P$. gracilis, que vocalizaram sobre o mesmo tipo de substrato diferiram na distância da margem; o contrário ocorreu com Chaunus ictericus, C. abei, L. ocellatus e $O$. americanus, que vocalizaram à mesma distância da margem mas diferiram no tipo de substrato utilizado. A ocorrência de complementaridade de nicho é um indício que a estrutura da comunidade é complexa e influenciada por vários fatores que interagem entre si (BEGON et al. 2006).

\section{Conservação da anurofauna}

A utilização de diversos hábitats e tipos de corpos d'água por anfíbios anuros evidencia a importância de se considerar a heterogeneidade ambiental no formato e delimitação de áreas de preservação, de modo a satisfazer os requisitos necessários na manutenção da diversidade de anuros.

Apesar da maioria das espécies encontradas na área de estudo estarem associadas a áreas abertas, verificou-se que cerca de $40 \%$ da anurofauna local (e.g. A. albosignatus, B. circumdata, S. catharinae, Leptodactylus aff. marmoratus, E. guentheri) ocorrem exclusivamente no interior e em borda florestal, sendo que algumas são espécies altamente dependentes de microhábitats de interior de floresta devido à exigência requerida por seus modos reprodutivos especializados (HADDAD \& PRADO 2005). Deste modo, a remoção dos fragmentos de floresta remanescentes na região pode provocar declínio populacional dessas espécies. Os remanescentes florestais são importantes também para espécies que se reproduzem em área aberta, como Trachycephalus imitatrix, que passou toda a estação não reprodutiva em remanescentes florestais, no interior de bromélias ou em cascas de árvores.

A modificação de hábitats é uma causa bem documentada no declínio de populações de anfíbios (Beebee 1996, Alford \& Richards 1999). A perda de hábitat pode alterar a abundância e a diversidade de espécies em áreas diretamente afetadas, sendo considerada de grande e rápido impacto na população de anfíbios, que podem perder os seus hábitats reprodutivos e/ou locais de abrigo e alimentação (Lips et al. 2005). O desmatamento que ocorreu e ainda ocorre na região Neotropical é responsável pela ameaça de extinção de várias espécies de anfíbios (HeYer et al. 1988, Papp \& Papp 2000, Garcia \& Vinciprova 2003, Segalla \& LANGONE 2004). A situação é mais crítica para a Floresta de Araucária, que foi quase totalmente destruída (BRitez et al. 2000), ameaçando espécies típicas dessa formação, como por exemplo Hypsiboas semiguttatus e Scinax catharinae (KwEt \& DIBernaRdo 1999). Mesmo que os fragmentos florestais da área de estudo sejam diferentes de uma floresta primária (KoEHLER et al. 
1998), devido à intensa exploração no passado, devem ser preservados para permitir a manutenção de espécies de anuros dependentes e/ou exclusivas dessa floresta.

\section{AGRADECIMENTOS}

Ao Peld/CNPq Ecossilvibras site 9: Conservação e Manejo Sustentável de Ecossistemas Florestais, pelo financiamento do projeto "Inventário faunístico da Fazenda Experimental Gralha Azul, PR"; a Sylvio P. Neto, decano do Centro de Ciências Agrárias e Ambientais, PUCPR, pelo constante apoio e incentivo a pesquisa. Ao diretor e a assistente técnica da Fazenda Experimental Gralha Azul, Luiz A. Kozlowski e Laureci M. Corradin, pelo apoio e logística. A Célio F.B. Haddad, Oswaldo L. Peixoto e Vanessa K. Verdade pela identificação de espécies. A Gledson V. Bianconi, Fabiana R. Mendes e Janael Ricetti pelas críticas e contribuições na versão preliminar. A Fernanda Stender e Anne D'Heursel pela tradução do resumo. Aos amigos e integrantes do projeto, Arthur A.B. de Oliveira, Gledson V. Bianconi, Janael Ricetti, Josiane S. Gruber e Rodrigo P. Di'Napoli. Ao Centro de Análise e Planejamento Ambiental, Rio Claro, São Paulo, ao Instituto Agronômico do Paraná, Londrina.

\section{REFERÊNCIAS BIBLIOGRÁFICAS}

Alford, A.R. \& S.J. Richards. 1999. Global amphibian declines: a problem in applied ecology. Annual Review of Ecology and Systematics 3: 133-65.

Arzabe, C. 1999. Reproductive activity patterns of anurans in two different altitudinal sites within the Brazilian Caatinga. Revista Brasileira de Zoologia 16 (3): 851-864.

Ayres, M; M. Ayres Jr; D.L. Ayres \& A.S. dos Santos. 2003. BioEstat 3.0 - aplicações estatísticas nas áreas das ciências biológicas e médicas. Belém, Sociedade Civil Mamirauá, 291p.

BEEBEE, T.J.C. 1996. Ecology and conservation of amphibians. London, Chapman \& Hall, VII+214p.

Begon, M.; J.L. Harper \& C.R. Towsend. 2006. Ecology: from individuals to ecosystems. London, Blackwell Publishing, $4^{\text {th }}$ ed., 752p.

Bernarde, P.S. \& L. dos Anjos. 1999. Distribuição espacial e temporal da anurofauna do Parque Estadual Mata dos Godoy, Londrina, Paraná, Brasil (Amphibia, Anura). Comunicações do Museu Ciências e Tecnologia da PUCRS, Série Zoologia, 12: 127-140.

Bertoluci, J. 1998. Annual Patterns of Breeding Activity in Atlantic Rainforest Anurans. Journal of Herpetology 32 (4): 607- 611.

Bertoluci, J. \& M.T. Rodrigues. 2002. Utilização de hábitats reprodutivos e micro-hábitats de vocalização em uma taxocenose de anuros (Amphibia) da Mata Atlântica do sudeste do Brasil. Papéis Avulsos de Zoologia 42 (11): 287-297.

Britez, R.M.; P.R. Castella \& L.A. Pires. 2000. Estratégia de conservação da floresta com araucária para o Estado do Paraná, p. 731-737. In: M.S. Milano \& V. Theulen (Eds). Campo Grande, Anais do Congresso Brasileiro de Unidades de Con- servação, XVI+845p. [ISSN 1677-1486]

Cardoso, A.J.; G.V. Andrade \& C.F.B. Haddad. 1989. Distribuição espacial em comunidades de anfíbios (Anuro) no sudeste do Brasil. Revista Brasileira de Biologia 49 (1): 241-249.

Castella, P.R.; R.M. Britez \& S.B. МıкICH. 2004. Áreas prioritárias de Floresta com Araucária para conservação no Estado do Paraná, p. 134-143. In: M.S. Milano \& V. Theulen (Eds). Curitiba, Anais do IV Congresso Brasileiro de Unidades de Conservação, V+718p. [ISSN 1677-1486]

Снао A. \& S.M. Lee. 1992. Estimating the number of classes via sample coverage. Journal of the American Statistical Association 87: 210-217.

Conte, C.E. \& D.C. Rossa-Feres. 2006. Diversidade e ocorrência temporal da anurofauna (Amphibia, Anura) em São José dos Pinhais, Paraná, sul do Brasil. Revista Brasileira de Zoologia 23 (1): 162-175.

Conte, C.E. \& R.A. Machado. 2005. Riqueza de espécies e distribuição espacial e temporal em comunidade de anfíbios anuros (Amphibia, Anura) em uma localidade do Município de Tijucas do Sul, Paraná, Brasil. Revista Brasileira de Zoologia 22 (4): 940-948.

CRump, M.L. 1971. Quantitative analysis of the ecological distribution of a tropical herpetofauna. Occasional Papers of the Museum of Natural History of the University of Kansas 3: 1-62.

CRUMP, M.L. 1974. Reproductive strategies in a tropical anuran community. Miscellaneous Publications Natural History University Kansas 61: 1-68.

Duellman, W.E. \& L. Trueb. 1986. Biology of amphibians. New York, McGraw-Hill Book Company, 670p.

Ferreira, J.C.V. 1996. O Paraná e seus municípios. Maringá, Memória Brasileira, 728p.

Garcia, P.C.A. \& G. Vinciprova. 2003. Anfíbios, p. 147-164. In: C.S. Fontana; G. Bencke \& R.E. Reis. (Eds). Livro vermelho da fauna ameaçada de extinção no Rio Grande do Sul. Porto Alegre, EdiPucRS, 623p.

Gosner, K.L. 1960. A simplified table for staging anuran embryos and larvae with notes on identification. Herpetologica 16: 183-190.

Haddad, C.F.B. \& C.P.A. Prado. 2005. Reproductive modes in frogs and their unexpected diversity in the Atlantic Forest of Brazil. BioScience 55 (3): 207-217.

Heyer, W.R.; A.S. Rand; C.A.G. Cruz \& O.L. Peixoto. 1988. Decimations, extinctions, and colonizations of frog populations in southeast Brazil and their evolutionary implications. Biotropica 20: 230-235.

HöDL, W. 1977. Call differences and calling site segregation in anuran species from Central Amazonian floating meadows. Oecologia 28: 351-363.

Koehler, A; S.P. Netto \& C.R. Sanquetta.1998. Análise da estrutura de uma Floresta Ombrófila Mista semidevastada, Fazenda Gralha Azul, Região Metropolitana de Curitiba, com implicações ao manejo. Revista Acadêmica 9 (1): 37-60. 
KreBs, C.J. 1999. Ecological methodology. Menlo Park, Addison Wesley Longman, 620p.

Kwet, A \& M. Di-Bernardo. 1999. Anfíbios. Rio Grande do Sul, EDIPUCRS, 108p.

Leite, P.E. \& R.M. Klein. 1990. Vegetação, p. 112-150. In: IbGe (Ed.). Geografia do Brasil: Região Sul. Rio de Janeiro, Instituto Brasileiro de Estatística e Geografia, vol. 2, 419p.

Lips K.R.; P.A. Burrowes; J.R. Mendelson III; \& G. Parra-Olea. 2005. Amphibian population declines in Latin America: a synthesis. Biotropica 37 (2): 222-226.

MAACK, R. 1981. Geografia física do Estado do Paraná. Rio de Janeiro, J. Olympio, 450p.

Machado, S.A. \& J.D.P. Siqueira. 1980. Distribuição natural da Araucaria angustifolia (Bert.) O Ktze, p. 4-9. In: Iufro meeting on forestry problems of the genus araucaria, 1. Curitiba, FUPEF, XVIII+382p.

PAPP, M.G.; \& C.O.G. PAPP. 2000. Decline in a population of the treefrog Phyllodytes luteolus after fire. Herpetological Review 31: 93-95.

Paraná. 1987. Atlas do Estado do Paraná. Curitiba, Secretaria de Estado da Agricultura e do Abastecimento. Instituto de Terras, Cartografia e Florestas, XI+73p.

Prado, C.P.A.; M. Uetanabaro \& C.B.F. Haddad. 2004. Breeding activity patterns, reproductive modes, and hábitats use by anurans (Amphibia) in a seasonal environmental in the Pantanal, Brazil. Amphibia-Reptilia 26 (2): 211-221.

Puc. 2007. Pontifícia Universidade Católica do Paraná: Fazenda Gralha Azul. Disponível em: http://www.pucpr.br/ educacao/auniversidade/fazgralhaazul [Acesso em fevereiro de 2007].

RABв, G.B. 1973. Evolutionary aspects of the reproductive behavior of frogs, p. 213-227. In: J.L. VIAL (Ed.). Evolutionary biology of the anurans: contemporary research on major problems. Columbia, University Missouri Press, 470p.

RohlF, F.J. \& R.R. SoKal. 1981. Comparing numerical taxonomic studies. Systematic Zoology 30: 459-490.

Rossa-Feres, D.C. \& J. JiM. 1994. Distribuição sazonal em comu- nidade de anfíbios anuros na região de Botucatu, São Paulo. Revista Brasileira de Biologia 54 (2): 323-334.

Rossa-Feres, D.C. \& J. Jim. 2001. Similaridade do sítio de vocalização em uma comunidade de anfíbios anuros na região noroeste do Estado de São Paulo, Brasil. Revista Brasileira de Zoologia 18 (2): 439-454.

ScotT JR, N.J. \& B.D. Woodward. 1994. Surveys at breeding sites, p. 118-125. In: W.R. Heyer; M.A. Donnelly; R.W. McDiarmid; L.A.C. НАYEK \& M.S. Foster (Eds). Measuring and monitoring biological diversity - standard methods for amphibians. Washington, Smithsonian Institution Press, XIX+364p.

Segala, M.V. \& J.A. Langone. 2004. Anfíbios, p. 537-577. In: S.B. Mikich, \& R.S. Bernils (Eds). Livro vermelho da fauna ameaçada no Estado do Paraná. Curitiba, Instituto Ambiental do Paraná, XVI+764p.

Tocher, M.D.; C. Gascon \& B.L. Zimmerman. 1997. Fragmentation effects on a Central Amazonian frog. community: a tenyear study, p. 124-127. In: W.F. LAURANCE \& R.O. BierRegaARD (Eds). Tropical forest remnants: ecology, management, and conservation of fragmented communities. London, The University of Chicago press, 616p.

Toledo, L.F; J. ZINA \& C.F.B. HadDAD. 2003. Distribuição espacial e temporal de uma comunidade de anfíbios anuros do Município de Rio Claro, São Paulo, Brasil. Holos Environment 3 (2): 136-149.

Valentin, J.L. 1995. Agrupamentos e ordenação, p. 27-55. In: P.R. Peres-Neto; J.L. Valentin \& F.A.S. Fernandez (Eds.) Tópicos em tratamento de dados biológicos. Rio de Janeiro, PPGE-UFRJ, Série Oecologia Brasiliensis II, XIV+161p.

Vasconcelos, T.S. \& D.C. Rossa-Feres. 2005. Diversidade, distribuição espacial e temporal de anfíbios anuros (Amphibia, Anura) na região noroeste do Estado de São Paulo, Brasil. Biota Neotropica 5 (2), disponível em: http://www. biotaneotropica.org.br/v5 n $2 / \mathrm{pt} /$ abstract?article+ BN01705022005 [acesso em 19/IX/2005].

ZAR, J.H. 1999. Bioestatistical analysis. New Jersey, Prentice Hall, 663p.

Recebido em 28.IX.2006; aceito em 19.XI.2007. 